\title{
Study of inter laminate layer effect on Impact and Hardness Properties for Unsaturated Polyester resin reinforced Hybrid Fabric composite
}

\author{
Hind W. Abdullah ${ }^{1 *}$ Ziad T. Khodair $^{2}$ Jasim M AL-Zanganawee ${ }^{3}$ Asaad A. Kamil $^{4}$
}

Department of physics, College of Science, University of Diyala, Iraq

${ }^{1}$ Email: hindwaleed@sciences.uodiyala.edu.iq

${ }^{2}$ Email: ziad_tariq@ sciences.uodiyala.edu.iq

${ }^{3}$ Email: assistprof.asaad@ sciences.uodiyala.edu.iq

*Corresponding author.

\section{Abstract}

In this research, we reported study of quality, sequential and directional layers for three types of fibers are woven perpendicular and random E- glass fiber and carbon chopped fiber effect on the impact and hardness shore (D) using as matrix unsaturated polyester. The composites were prepared by hand lay-up method. The composites constituents were unsaturated polyester using a matrix with $25 \%$ volume fractions of Glass Fibers (G.F) as reinforcement and 5\% carbon chopped fiber as hybrid fabric composite. The results showed that the non - reinforced unsaturated polyester have lower properties than composites material tests are conducted on these specimens to determine the at maximum load and hardness number using a universal testing machine and hardness shore (D) testing machine. Different behavior was shown for the fiber/polyester composite depending on the type of the fiber. The sample which reinforced three layers fiberglass characterized the highest impact strength of these composites due to high chemical compatibility between reinforced materials (fiber and matrix) base resin polyester.

Keywords: Hybrid composite, unsaturated polyester, glass fiber, carbon chopped fiber, impact test, hardness shore (D).

\section{Introduction}

Thermoset polymer composites are an important class of engineering materials secondhand in modern-day engineering applications. Thermosetting resin like epoxy is widely used in various engineering applications starting from automobile industries to the aerospace application[1]. Hybrid composites are one of the emerging fields in polymer science that are gaining attention for application in various sectors as building, aeronautical and automotive. The concept of hybridization provides flexibility to the design engineer to tailor the material properties according to particular requirements and 
the behavior of the hybrid composites appears to be, in general, a weighted sum of the contributions of the individual components in which there is a balance between their advantages and disadvantages[2]. Fiber reinforced composites have become the alternatives of conventional structural materials such as steel, wood or metals in many applications. Typical areas of composite applications are car industry, aircraft fabrication, wind power plant, boats, ships, etc.[3]. Unlike the traditional synthetic fibers like glass and carbon, the plant fibers are able to impart certain benefits to the composites such as low density, high stiffness, low cost, renewability, biodegradability, environmentally friendly and high degree of flexibility during processing [3]. The most important polymer in glass fiber reinforced composite is unsaturated polyester, In the last years it conceders as one of the most famous composites because of its reasonable mechanical properties, low cost and easily fabrication techniques which include: spray, hand lay-up reactive injection modeling and resin transfer. The properties of a hybrid composite mainly depend upon the fiber content, length of individual fiber, orientation, extent of intermingling of fibers, fiber to matrix bonding and arrangement of both the fibers. The strength of the hybrid composite is also dependent on the failure strain of individual fibers .Maximum hybrid results were obtained when the fibers are highly strain compatible [4]. The review also showed that the shape of the stress-strain curves for hybrid composites varies with the different type of fibers and resins used, the overall fiber fraction and the orientation of the reinforcement in the material. The positive hybrid effect was observed in flexure tests of specimens with high glass versus carbon fiber ratio; however, the compression and fracture energy of glass/carbon epoxy matrix composites exhibited the negative hybrid effect. In a recent study, the tensile and compressive loading cases on hybrid glass/carbon fabric composites have been investigated and the main observation of this work is that by placing glass fabric layers in the exterior and carbon fabric layers in the interior, higher tensile strength and ultimate tensile strain were obtained [5].

\section{Experimental work}

\section{Material used}

The matrix used in this study was unsaturated polyester resin (UPE) type (A-50), hardener MEKP with accelerator cobalt naphthenate supplied by IPI Jordan were used. The typical properties of unsaturated polyester resin are shown in Table (1). Volume fraction of matrix [6]. :

$$
\mathrm{V}_{\mathrm{m}}=\frac{V m}{V c} \%
$$

Reinforcing material : 
1- E- Glass fiber :Uniform(GW) and $\operatorname{random}(\mathrm{GR})$ were illustrated in Fig(1).

2- carbon chopped fiber, Volume fraction of fiber :

$$
\mathrm{V}_{\mathrm{f}}=\frac{V f}{V c} \text {. }
$$

Table (1). Typical properties of unsaturated polyester resins

\begin{tabular}{|c|c|c|c|c|c|}
\hline Property & $\begin{array}{c}\text { Density } \\
\left(\mathrm{gm} / \mathrm{cm}^{3}\right)\end{array}$ & $\begin{array}{c}\text { Tensile } \\
\text { strength } \\
(\mathrm{MPa})\end{array}$ & $\begin{array}{c}\text { Tensile } \\
\text { modulus } \\
(\mathrm{GPa})\end{array}$ & $\begin{array}{c}\text { Cure } \\
\text { shrinkage\% }\end{array}$ & $\mathrm{T}_{\mathrm{g}}(\mathbf{k})$ \\
\hline $\begin{array}{c}\text { Unsaturated Polyester } \\
\text { (UPE) }\end{array}$ & $1.05-1.4$ & $45-103$ & $45-103$ & $45-103$ & $45-103$ \\
\hline
\end{tabular}

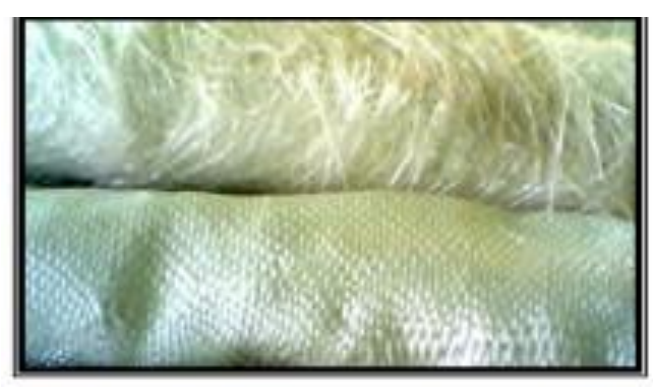

(A ). Glass fiber

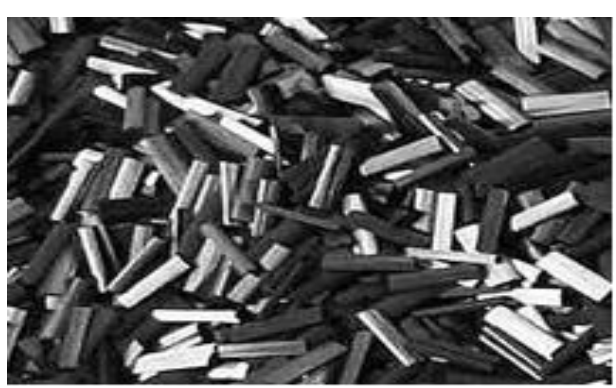

(B) Carbon chopped fiber

Fig (1). Types of fibers were used in this work.

\section{Sample Preparation}

Hand - layup method was used to fabricate UPE composite. The composites constituents were unsaturated polyester using as matrix with $25 \%$ volume fractions of glass Fibers (G.F) as reinforcement and 5\% carbon chopped fiber as hybrid fabric composite. The laminates were fabricated by placing the glass fiber one over the other with a matrix in between the layers and three layers from glass fiber (0-90) as well as UPE composites, three layers of glass random fiber and then (glass fiber (0-90)- glass random fiber - glass fiber (0-90) ) hybrid composite was fabricated in the shape as : glass fiber (0-90) - 5\%carbon chopped fiber - glass fiber (0-90). The laminates were left to solidify at room temperature $(26 \mp 2){ }^{\circ} \mathrm{C}$. The glass mould of frame was $(10 \times 10 \times$ 4) $\mathrm{cm}$ used for casting the laminates of composite material. It Wax was fixed on the inner mound faces before casting to ensure the releasing of casting composites and having smooth faces. 


\section{Impact test}

An Impact testing machine (Charpy impact test instrument) was used for the testing of the composite specimen for its Impact strength. The device consists of a pendulum of known mass and length that is dropped from a known height to impact of material The energy transferred to the material can be incidental by comparing the difference in the height of the hammer before and after the fracture. The impact resistance and impact strength of the composites were obtained at room temperature.

\section{Hardness test (shore D)}

This test is performed by using hardness (Shore D) and according to (ASTM DI-2240) the standard at room temperature.. We used Durometer Hardness the instrument by ( shore D) that is fabrication by ( time group Inc) company to execute the hardness test by wing pointed dibbing tool, which penetrates the material surface by the pressure applied to the instrument where the dibbing tool head touching quite the surface of the samples, then we see the value of the sample hardness recorded on the screen of the instrument.

\section{Results and Discussions}

\section{Impact test}

The conventional Charpy impact test is used to evaluate the impact strength of UPE and fabrics composites. The results of this test are shown the values of the prepared samples in Tables (2). The results showed that the unsaturated polystyrene resin plastic behaves When the shock test is performed, the energy will be concentrated in the impact region, which is located in the middle of the sample. This will absorbed energy for the purpose of pay off it. Which showed shock resistance of $5.88 \mathrm{~kJ} / \mathrm{m}^{2}$. During the testing process, the specimen must be loaded in the testing machine and allows the pendulum to break the specimen. Using the impact test, the maximum energy needed to break the material can be measured easily.

The fabric composite showed that the direction of the fibers played an important role in determining the mechanical behavior of the consistent. The impact strength of the e carbon chopped fibers composites is greater than of the pure(UPE) that because carbon chopped fibers were environmentally neutral with a low smoke density rating and low smoke emission[7]. The material is drawn into fibers and kept under tension while it is heated to high temperature $\left(>1000^{\circ} \mathrm{C}\right)$ dimensional carbon-carbon crystals (graphite) are formed when the hydrogen is driven out. The carbon-carbon chain has extremely strong molecular bonds and that is what gives the fibers its superior mechanical 
properties[8]. While the results exposed that the durability of the impact strength increases by increasing the number of layers of glass(0-90) fibers of the composite in the three types of samples (A5-A3-A4), this is due to the woven fibers(0-90) has abided most of the impact strength due to the characteristic of these fibers of (0-90) woven in length and homogeneity, and therefore the resistance to impact strength has increased after the reinforcement, fibers orientation and fibers volume fraction are important microstructure parameters in the impact characterization of fabric composite[10], Fig.(2) which show the effect of content reinforcement fibers on the impact strength values of the prepared samples. When the resin is reinforced with carbon fibers as an intermediate layer of glass fibers a hybrid, the diffusion mechanism is different from the previous one. The being there of fibers inside the resin will inhibit the spread of the cracks [9]. The spread of the crack during the resin material and the passage of the crack through the fiber (cut off the fiber) or its growth through the passage of the splitting between the area of bonding is due to the increase in the proportion of fibers glass will make the material (resin) less diffused between the fiber and thus to the behavior corresponding is a brittle behavior of resin, meaning that the energy exhausted on plastic deformities is less than the previous one, thus reducing the impact strength values compared to the samples (A4-A3). The experimental test series showed an increased deflection of carbon chopped composite, which led to a higher extent of material damage as compared to glass fibers laminates with energy absorption capacity being fibers laminates with energy absorption capacity being lower in carbon chopped / UPE laminates as compared to glass fibers /UPE laminates From the above carbon chopped / UPE results has less impact strength than glass fibers/UPE laminates.

Table (2) Impact strength, impact energy and Dimensions of all samples.

\begin{tabular}{|c|c|c|c|c|c|c|}
\hline S.No & Type of specimen & $\begin{array}{l}\text { Width } \\
\text { (d) } \mathrm{mm}\end{array}$ & $\begin{array}{l}\text { Thickness } \\
\text { (S) } \\
\text { (mm) }\end{array}$ & $\begin{array}{c}\underset{\left(\mathbf{m}^{2} \times 10^{-6)}\right.}{\operatorname{Area} A}=\mathbf{S} \times \mathbf{d} \\
\end{array}$ & $\begin{array}{l}\text { Impact } \\
\text { Energy } \\
\text { (Joul) }\end{array}$ & $\begin{array}{c}\text { impact } \\
\text { strength } \\
\mathbf{G}_{\mathrm{C}}\left(\mathbf{K J} / \mathbf{m}^{2}\right)\end{array}$ \\
\hline A0 & UPE & 0.01 & 0.0034 & 34 & 0.2 & 5.88 \\
\hline A1 & Carbon fiber /UPE & 0.01 & 0.0034 & 34 & 0.95 & 27.94 \\
\hline $\mathbf{A 2}$ & $\begin{array}{l}\text { Glass(0-90)-carbon } \\
\text { 5\% - glass }(0-90) \text { fibers } \\
\text { /UPE }\end{array}$ & 0.01 & 0.0034 & 34 & 1 & 29.41 \\
\hline $\mathbf{A 3}$ & $\begin{array}{l}\text { 3Layers glass } \\
\text { random/UPE }\end{array}$ & 0.01 & 0.0034 & 34 & 1.05 & 30.88 \\
\hline A4 & $\begin{array}{l}\text { Glass(0-90)-glass random- } \\
\text { glass(0-90) /UPE }\end{array}$ & 0.01 & 0.0034 & 34 & 1.5 & 44.11 \\
\hline A5 & $\begin{array}{l}\text { 3Layeres glass } \\
(0-90) / \text { UPE }\end{array}$ & 0.01 & 0.0034 & 34 & 2.35 & 69.11 \\
\hline
\end{tabular}




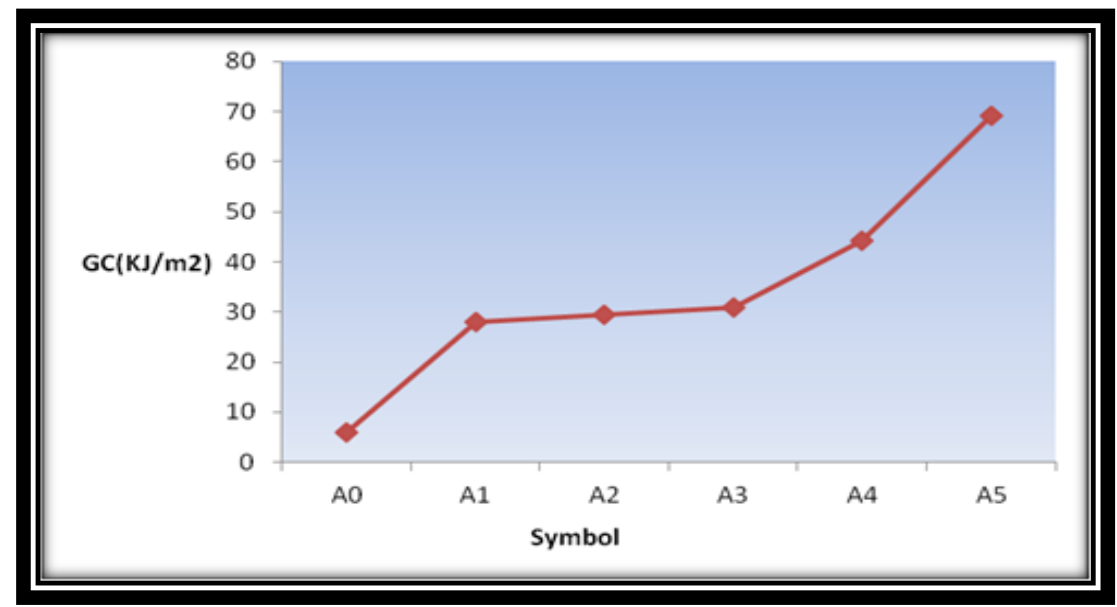

Fig.(2) Impact Strength of UPE/Fabric composite

\section{Hardness test}

Hardness is extensively used to characterize materials and to determine if they are suitable for their intended use. The most common uses for hardness tests is to verify the heat treatment of a part and to determine if a material has the properties necessary for its intended use[11], Fig (3) shows the hardness property of the composite reinforced with the fibers. The results of this test are shown the values of hardness were illustrated in table (3) increased it with increasing the numbers of layers (0-90) glass fibers, because of the effect of orientation of fibers (distribution in the matrix) which has the major role in the mechanical behavior of the composite[12]. While in the composite reinforced with random fibers, the load is concentrated at the end of short fibers(carbon chopped fiber) and the alignment of fibers are randomly distributed in the matrix which makes the control of transmission of the load from the matrix to the fibers in the interface region are weak [13].

Table (3) Hardness Shore -D of all samples

\begin{tabular}{|c|c|c|c|}
\hline S.N & Type of specimen & $\begin{array}{c}\text { Hardness Shore-D } \\
\left(\mathbf{N} / \mathbf{m m}^{2}\right)\end{array}$ & $\begin{array}{c}\text { Thickness } \\
(\mathbf{m m})\end{array}$ \\
\hline A0 & UPE & 78.5 & $\mathbf{0 . 0 0 3 4}$ \\
\hline A1 & Carbon fiber /UPE & 80.5 & 0.0034 \\
\hline A2 & $\begin{array}{c}\text { Glass(0-90)-carbon 5\%- glass } \\
(\mathbf{0 - 9 0}) \text { fibers /UPE }\end{array}$ & $\mathbf{8 1}$ & $\mathbf{0 . 0 0 3 4}$ \\
\hline A3 & 3Layers glass random/UPE & 82 & $\mathbf{0 . 0 0 3 4}$ \\
\hline A4 & Glass(0-90)-glass random-glass(0-90) & 84.5 & $\mathbf{0 . 0 0 3 4}$ \\
\hline A5 & 3Layeres glass (0-90)/UPE & 86.16 & $\mathbf{0 . 0 0 3 4}$ \\
\hline
\end{tabular}




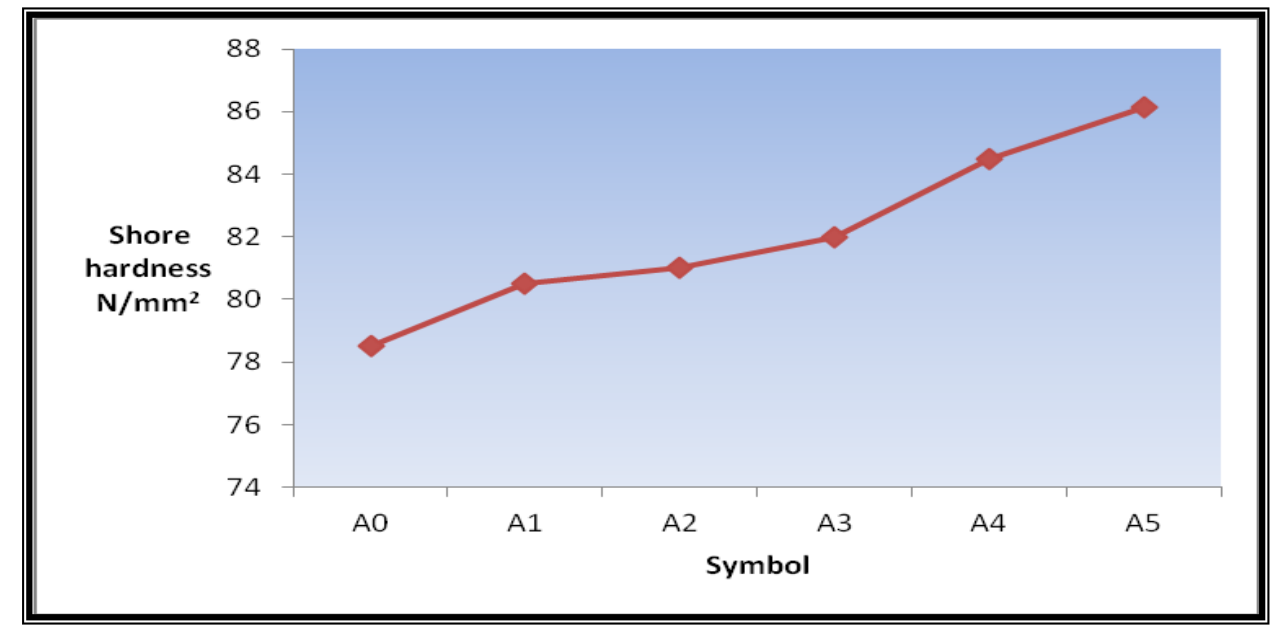

Fig (3) Hardness shore-D of UPE/Fabric composite

\section{Conclusions}

The following conclusions are dragged from the experimental investigations

1 - The impact resistance of epoxy had increased due to positive role fibers reinforcement.

2- The combination of reinforcement such as glass fiber and carbon chopped fiber in composite laminates improves the mechanical strength and this makes way to the increase of the utilization of fibers in various application

3- Effect of fiber loading and orientation on mechanical properties (impact strength hardness ) of carbon chopped and glass fiber reinforced polymer based hybrid composites.

4-Effect of kind fiber as interlaminate of composite in in determining the mechanical behavior of the tests .

5- The results of sandwich composite show a linear increasing glass fiber(0-90) layers.

\section{References}

1- Akash Mohanty, V. K. Srivastava," Compressive failure analysis of alumina nano particles dispersed short glass/carbon fiber reinforced epoxy hybrid composites." International Journal of Scientific \& Engineering Research, Volume 3, Issue 11, November (2012).

2- Ademir J. Zattera, Daiane Romanzini, Alessandra Lavoratti, Heitor L. Ornaghi Jr Sandro $\quad$ C. Amico," Influence of fiber content on the mechanical and dynamic mechanical properties of glass/ramie polymer composites." Materials and Design Elsevier Ltd. Vol. 47,

(2013) 915. 
3-G. Seshanandan, D. Ravindran and T. Sornakumar," Mechanical properties of nano titanium oxide particles - hybrid jute-glass FRP composites." / Materials Today: Proceedings Elsevier Ltd ,V( 3) (2016) 1383-1388.

4- Parul Roll," Glass fiber /Epoxy Polymer Nano composites effect of another polymeric fiber. Master Of technology in chemical Engineering, THAPAR University, India, June (2013).

5-Amal A.M. Badawy," Impact behavior of glass fibers reinforced composite laminates at different temperatures." Ain Shams Engineering Journal, Elsevier Ltd,Vol.(3),(2012),11115 .

6- Sumite Mahajan," Epoxy Layered Silicate Nano composites as Matrix in Fiber Reinforced composites" M.Sc., Thapar University, India , 2011.

7-Sameer S. Rahatekar, Mauro Zammarano, Szabolcs Matko Krzysztof K. Koziolb, Alan H. Windleb, Marc Nyden, Takashi Kashiwagi, and Jeffrey W. Gilman," Effect of carbon nanotubes and montmorillonite on the flammability of epoxy nanocomposites." Polymer Degradation and Stability Volume 95, Issue 5, May( 2010), Pages 870-879.

8- James F. Shackelford, " Introduction Material Science For Engineers" University of Califon by Peason Enduction , (2009).

9- Mohammed Sellab Hamza," Study the Effect of Fibers Volume Fraction and their Orientations on the Properties of the Hybrid Composite Materials." , Eng. \&Tech. Journal, Vol.31, Part (A), No.13, 2013.

10- Hibbeler R.C, "Mechanics ofnMaterials", 6th Ed, Pearson prentice Hall, (2005).

11- J. Abenojar, M.A. Martínez, F. Velasco, J.C. del Real-Romero, "Effect of moisture and temperature on the mechanical properties of an epoxy reinforced with boron carbide", Journal of Adhesion Science and Technology. Volume: $25 \mathrm{~N}$ : 18. August (2011), PP (2445- 2460).

12-NurulW.Rusl,Mohmad B. AbdBakar, MohdZ, AhmedT.,Muhammad A.Sulalman,Mhodanad N.Masr ,"Flexural and Morphology properties of kenaf fiber reinforcement unsaturated polymer composite." Materials science Forum, Vol.888,(2017),p(193-197).

Emad S. Al-Hasani," Study of Tensile Strength and Hardness Property for Epoxy Reinforced With Glass Fiber Layers.", Eng. \& Technology, Vol.25, No.8(,2007). 